\title{
Determinants of Costs and the Length of Stay in Acute Coronary Syndromes: A Real Life Analysis of More Than 10000 Patients
}

\author{
Matthias Bramkamp • Dragana Radovanovic • \\ Paul Erne • Thomas D. Szucs
}

Published online: 6 September 2007

(C) Springer Science + Business Media, LLC 2007

\begin{abstract}
Aims The aim of this study was to investigate inpatient costs of acute coronary syndromes (ACS) in Switzerland and to assess the main cost drivers associated with this disease.

Methods and Results We used the national multicenter registry AMIS (acute myocardial infarction in Switzerland) which includes a representative number of 65 hospitals and a total of 11.623 patient records. The following cost modules were analyzed: hospital stay, percutaneous coronary interventions (PCI) and thrombolysis. Expenses were assessed using data from official Swiss national statistical sources. Mean total costs per patient were 12.101 Euro (median 10.929 Euro; 95\% CI: 1.161-27.722 Euro). The length of stay ranged

The authors state that their study complies with the Declaration of Helsinki, that the locally appointed ethics committee has approved the research protocol and that informed consent has been obtained from the subjects (or their guardians).
\end{abstract}

Paul Erne is a co-author on behalf of the AMIS Plus Investigators.

M. Bramkamp $(\bowtie)$

Department of Internal Medicine, University Hospital of Zurich,

RAE B 40, Rämistr. 100,

CH-8091 Zurich, Switzerland

e-mail: Matthias.Bramkamp@usz.ch

D. Radovanovic

AMIS Plus Data Center, Institute for Social and Preventive

Medicine, University of Zurich,

Hirschgraben 84,

CH-8001 Zürich, Switzerland

P. Erne

Department of Cardiology, Kantonsspital Lucerne,

6000 Lucerne 16, Switzerland

T. D. Szucs

Institute for Social and Preventive Medicine, University of Zurich,

Hirschgraben 84,

CH-8001 Zürich, Switzerland from one to 129 days with a mean of 9.5 days (median 8.0 days; 95\% CI: $1-23$ ). Overall costs were independently influenced by age, gender and existent co-morbidities, e.g. cerebrovascular disease and diabetes $(p<0.0001)$.

Conclusion Our study determined specific causes for the high costs associated with hospital treatment on a large representative sample. The results should highlight unnecessary expenses and help policy makers to evaluate the base case for a DRG (Diagnosis Related Groups) scenario in Switzerland. Cost weighting of the identified secondary diagnosis should be considered in the calculation and coding of a primary diagnosis for ACS.

Key words acute coronary syndromes · cost analysis · cost predictors $\cdot$ diagnosis related groups

\section{Introduction}

CVD (cardiovascular disease) is a common and costly medical condition in all populations. It is the leading cause of death worldwide. Nearly 3.8 million men and 3.4 million women worldwide die each year from coronary heart disease. CVD causes over 4.35 million deaths in Europe and over 1.9 million deaths in the European Union (EU) each year. Nearly half of all deaths in Europe (49\%) and the EU (42\%) arise from CVD. It is the main cause of years of life lost from early death in Europe and the EU. A third of the years of life lost from early death result from CVD. Overall CVD is estimated to cost the EU economy 169 billion Euros annually of which approximately $62 \%$ is due to health care expenses, $21 \%$ due to productivity losses and $17 \%$ due to informal care of people with CVD [1].

In Switzerland CVD is the most frequent cause of death. It affects $42 \%$ of women and $35 \%$ of men and accounts for 
$38 \%$ of all deaths. Between 1999 and 2002 more than 186 out of 100.000 inhabitants annually died from CVD [2]. According to the International Classification of Diseases (ICD-10), 135.341 patients suffering from CVD had been treated in Switzerland in 2004.

CVD accounted for $3.1 \%$ of all hospital diagnoses in 2004 in Switzerland. With 1.258391 in hospital care days CVD is within the top three ranking of ICD related national hospital stay [3]. The expenditures for inpatient treatment are expected to rise from more than 25 million CHF (16.13 million Euros) in 2005 to more than 27 million CHF (17.42 million Euros) in 2007. Among the countries in the Organisation for Economic Co-operation and Development (OECD), Switzerland ranks second $(11.5 \%)$ behind the USA $(15 \%)$ in terms of healthcare expense versus gross domestic product (GPD). Switzerland (8 days) also ranks second behind Germany ( 9 days) in terms of length of hospital stay [4].

The increasing health care budget draws public interest to significant economic impacts on the Swiss health care system.

ACS (acute coronary syndrome) is a continuum of acute ischemic cardiac conditions. ACS is defined as non-STsegment elevation myocardial infarction (NONSTEMI), STsegment elevation myocardial infarction (STEMI), and unstable angina (UA) [5].

Only a few studies have compared the medical costs of ACS from a European perspective, and involve only a small non-representative number of Swiss data $[1,6,7]$.

None of these studies identifies the main causes of expenses in patients suffering from ACS within a nationwide multicenter database of the Swiss population.

Analysis of factors that increase or decrease the length of hospital stay of patients with underlying myocardial infarction is of interest from both a medical quality and pecuniary standpoint. The implementation of DRGs will allow nationwide comparative assessments of resource use and costs. The amount of money spent in CVD will be of particular importance.

The DRG system fixes the amount of treatment on the basis of discharge activity. This system is composed of different major diagnostic categories which further compound several DRG categories. A discharge in a DRG practiced system receives a weight that has been given to this group. This weight represents the average use of resources in relation to the discharge. These cost weights are determined by using a trimming average for cost and the length of hospitalization. A maximum and minimum hospitalization length of time and cost for each DRG group is computed. For this purpose a censured intersection is assessed. Exceeding the length of stay from the trimming point in a given DRG group connotes a defined extra cost for each bed day. The aim of this study was to investigate inpatient costs of ACS in Switzerland and to assess the main cost drivers associated with this disease.

\section{Methods}

Patients

Calculations had been based on an AMIS database population of 11.623 patients admitted to a hospital for ACS from January 1997 until December 2005.

The AMIS registry collects and analyzes data of patients with ACS in Switzerland in the pre-admission and hospital phases. Emphasis is placed on the evaluation of risk factors, diagnostics, urgent therapy strategies, and treatment of ACS. Patients are grouped in the database on the basis of their final diagnosis, which must comply with one of the three following definition categories: AMI (acute myocardial infarction), symptoms or ECG (electrocardiogram) changes compatible with ACS, or both, and cardiac enzymes (total creatinine kinase $[\mathrm{CK}]$ or [CK-MB] at least twice the upper limit of normal range); ACS with minimum necrosis (symptoms or ECG changes compatible with acute coronary syndrome, or both, and cardiac enzymes (total CK or CK-MB) lower than twice the upper limit of normal range, and positive troponin); and UA (symptoms or ECG changes compatible with ACS, or both, and normal cardiac enzymes). Cases that are unclear or non-cardiac cases are excluded.

The registry started in 1997 and continues to add patient cases. To date, 65 of the 106 hospitals treating ACS in Switzerland are enrolling patients, ranging from community to large university hospitals. Participating centers add blind data for each patient through a standardized internet or paper based questionnaire. The data are centralized at the Institute for Social and Preventive Medicine at the University of Zurich, where they are monitored for plausibility and consistency. The registry was authorized by the AboveRegional Ethics Committee for Clinical Studies and the Swiss Board for Data Security.

The questionnaire comprises 140 items for each patient and is completed by the coordinator of each institution. It asks information regarding medical history and existing co-morbidities, known cardiovascular risk factors, acute symptoms, out of hospital management, clinical presentation, early (first $48 \mathrm{~h}$ ) in-hospital management, reperfusion therapy, hospital course, diagnostic tests used or planned, hospital length of stay, discharge medication and destination. The documented data from 11.623 patients with ACS were analyzed.

\section{Cost evaluation}

Reliable hospital related cost estimates are difficult to obtain in Switzerland. Differences exist in measuring patient costs among the individual Swiss cantons and in-between the hospitals of each canton. 
Some hospitals balance accounts by prospective lump compensation while others allocate individual performance. Even the invoiced amount per entries varies between the hospitals. Some cantons apply a singular flat rate (funded half and half between the local canton and the insurance company) and a per day rate. The flat rate includes all care performed except prescription of high priced pharmaceuticals, days spent on the intensive care unit (ICU) and high priced implants (e.g. drug eluting stent).

These rates differ between the type of department (e.g. surgery or rheumatology), on the level of insurance (private, semi-private or compulsory health insurance) and the geographic policy territory of the involved health insurance company. The insured patient is required by law to apply for specific high cost treatments in the canton of residency. For medical service outside of the canton a separate fee is applied and calculated.

To obtain a nationwide representative overview we assessed expenses using data from official Swiss national statistics [8]. The cost evaluation was made from the perspective of a hospital. The calculation is based on adapted average charges per hospital care day without investment costs. These come from a division of the charges per hospital care day without investment costs through the case mix gross of the hospital.

One day of hospital care in a university hospital costs up to 1.308 Euro while a smaller hospital charges 483 Euro. One cause for the apparent tripling of cost is that the costs in this indicator are not measured according to the severity code of the medical condition. Patients suffering from critical illness have longer hospital stays and require more nurse care depending on the severity of the disease. A university clinic also incurs expenditures for teaching, research and development.

Statistics for average hospital care charges can be refined by employing a case mix calculation. A case mix calculation takes the severity code into account. By comparing the average adapted costs and the average cost per hospital care day with investment costs, the influence of the severity code can be taken into account.
The type of activity and duties of a hospital have a huge impact on the average costs per hospital day. Similar sized hospitals (beds, personal, total charges) can feature varying amounts of hospital per day fees. These depend on the type of disease and treatment (acute versus long term treatment). The effects can be taken into consideration by using a weighting of the average costs per hospital care day through the case mix gross. This indicator comes with DRG strings attached. Each DRG group is allocated to a special case mix that indicates the economic performance indicator related to a reference average of one. Only inpatient cases of the hospitals are considered while ambulant ones are excluded.

This model was generated for five categories of hospitals arranged according to their size. The categories are defined by the number of treated patients per year and the number of medical specialist categories (Table 1).

Per day costs for a small hospital were averaged to 548 Euro. Larger hospitals averaged 806 Euros and centralized hospitals averaged 758-up to 839 Euros per day. University hospitals charge 1.129 Euro per day. The national average charge for all types of hospitals, which acted as a calculation base for the hospital charges in our evaluation, is 816 Euro per care day (based on the latest collected case mix statistic data, 2003). Using this method a flat rate is included in the total.

Our hospital based perspective did not account for costs associated with morbidity or mortality (e.g. productivity losses).

Table 2 shows other parameters of the cost calculation. Rates for ICU were computed to be 2.435 Euro per day. PCI costs 1.548 Euro and the accrued expenses for thrombolysis amounted to 1.161 Euro. These were estimated as an average peak cost for all available data. Swiss francs were converted to Euro with an exchange rate of 1.55 (15.5.2006) [9].

\section{Statistical analysis}

Data concerning the costs and length of hospitalization were analyzed according to different factors. Age, gender, co-

Table 1 Hospital size and calculation of case mix adapted charges per hospital care day (1999-2003) [4]

\begin{tabular}{|c|c|c|c|c|c|}
\hline Hospital & Code & $\begin{array}{l}\text { Number of treated } \\
\text { cases per year }\end{array}$ & $\begin{array}{l}\text { Number medical } \\
\text { specialities }\end{array}$ & $\begin{array}{l}\text { Expected number } \\
\text { of hospitals }\end{array}$ & $\begin{array}{l}\text { Case mix adapted charges per } \\
\text { hospital care day in Euro }\end{array}$ \\
\hline $\begin{array}{l}\text { Centralized medical care type } 1 \\
\text { university hospital }\end{array}$ & 1 & $>30.000$ & $\geq 100$ & 5 & 1.129 \\
\hline Centralized medical care type 2 & 2 & $9.000-30.000$ & $100>\sum$ specialist $\geq 20$ & 22 & 839 \\
\hline Primary medical care type 1 & 3 & $6.000-9.000$ & $20>\sum$ specialist $\geq 10$ & 28 & 758 \\
\hline Primary medical care type 2 & 4 & $3.000-6.000$ & $10>\sum$ specialist $\geq 5$ & 55 & 806 \\
\hline Primary medical care type 3 & 5 & $<3.000$ & $<5$ specialist & 53 & 548 \\
\hline
\end{tabular}

Hospital categories and service area: type 1 huge; type 2 middle; type 3 small 
Table 2 Parameters of cost calculation and mean cost per patient for each resource category

\begin{tabular}{lllllll}
\hline Resource use & Unit costs in Euro & Number & Cost mean & Cost median & Standard deviation & $\%$ of total costs (\%) \\
\hline Hospitalization & 816 & 11.623 & 6.906 & 5.713 & 6.632 & 57.07 \\
ICU & 2.435 & 9.569 & 4.151 & 2.435 & 4.717 & 34.30 \\
Thrombolysis & 1.161 & 3.347 & 334 & NM & 526 & 2.76 \\
PCI & 1.548 & 5.327 & 710 & NM & 772 & 5.87 \\
Total & & 11.623 & 12.101 & 10.929 & 9.218 & 100 \\
\hline
\end{tabular}

morbidities, smoking status and body mass index (BMI) are risk factors associated with ACS and have been positively identified with having a correlation in previous studies [10-12].

All data were analyzed with SPSS (version 12.0) for Windows NT.

An assessment of univariate associations between candidate predictors and costs was performed by the non-parametric Mann-Whitney rank sum test. $T$-test or ANOVA were used for categorical independent variables. A two tailed probability value of $p<0.05$ was considered to be significant.

A multivariate linear regression model for predicting the cost and length of stay was used for the following variables: gender, age, BMI, insurance coverage, smoking, history of ACS, co-morbidities, cardiac insufficiency NYHA III-IV, peripheral vascular disease, cerebrovascular disease, diabetes, renal disease, arterial hypertension and dyslipidemia.

Separate univariate linear models were first fitted for each variable and then backwards eliminated against a significance level of 0.05 . Odds ratios were simultaneously adjusted for all other predictors included in the multivariate linear regression mode. Independent variables showing a positive assignment to costs were treated as candidates for multivariate regression analysis.

Descriptive statistics are presented as percentages for discrete variables. For data not normally distributed a median and an interquartile range is calculated. For normally distributed data a mean confidence interval is calculated. Calculations of total charges and the length of hospital stay are indicated with both a mean and a median. Thus the best estimated costs and duration of stay per patient and per typical patient are reflected.

\section{Results}

We analyzed 11.623 patients admitted for ACS from January 1997 until December 2005. Of these patients, 73\% were male and $27 \%$ female. Of the patients analyzed, 10.827 patients were found to have an ECG ST-segment elevation at hospital admission. Patients were treated in accordance with international guidelines [13-16]. Table 3 illustrates the baseline characteristics of the study population.
Patient population and co-morbidities

The mean age of the study patients was $64.4 \pm 13.3$ years (median 66.18 years; in males $63.12 \pm 12.99$ years; median

Table 3 Baseline characteristics, co-morbidities and associated prevalence of the study population

\begin{tabular}{|c|c|c|}
\hline & Number & Percent \\
\hline Hospital admission & 11.623 & 100 \\
\hline Women & 3.140 & 27 \\
\hline Men & 8.483 & 73 \\
\hline \multicolumn{3}{|l|}{ Age } \\
\hline$<65$ & 5.492 & 47.3 \\
\hline$\geq 65$ & 6.131 & 52.7 \\
\hline \multicolumn{3}{|l|}{ BMI } \\
\hline$<25 \mathrm{~kg} / \mathrm{m}^{2}$ & 3.349 & 28.8 \\
\hline$\geq 25 \mathrm{~kg} / \mathrm{m}^{2}$ & 5.547 & 47.7 \\
\hline No answer & 2.727 & 23.5 \\
\hline \multicolumn{3}{|l|}{ Smoking } \\
\hline Never & 3.883 & 33.4 \\
\hline Former & 2.489 & 21.4 \\
\hline Current & 4.614 & 39.7 \\
\hline No answer & 637 & 5.5 \\
\hline \multicolumn{3}{|l|}{ Killip classification } \\
\hline I & 8.490 & 73 \\
\hline II & 2.045 & 17.6 \\
\hline III & 550 & 4.8 \\
\hline IV & 336 & 2.9 \\
\hline No answer & 202 & 1.7 \\
\hline \multicolumn{3}{|l|}{ ST segment elevation } \\
\hline Yes & 10.827 & 93.2 \\
\hline No & 777 & 6.7 \\
\hline No answer & 19 & 0.2 \\
\hline \multicolumn{3}{|l|}{ Diabetes } \\
\hline Yes & 2.160 & 18.6 \\
\hline No & 9.063 & 78.0 \\
\hline No answer & 400 & 3.4 \\
\hline \multicolumn{3}{|l|}{ Hypertension } \\
\hline Yes & 5.740 & 49.4 \\
\hline No & 5.380 & 46.3 \\
\hline No answer & 503 & 4.3 \\
\hline \multicolumn{3}{|l|}{ Dyslipidemia } \\
\hline Yes & 5.827 & 50.1 \\
\hline No & 4.661 & 40.1 \\
\hline No answer & 1.135 & 9.8 \\
\hline
\end{tabular}


Table 4 Outcomes and in hospital procedures

\begin{tabular}{lll}
\hline Outcome/procedure & Number & Percent \\
\hline Death & 1.024 & 8.81 \\
Alive discharge & 10.597 & 91.19 \\
Patients received PCI & 5.327 & 45.83 \\
Patients received thrombolysis & 3.347 & 28.80 \\
Average days hospital stay & 9.48 & \\
Average days stay women & 11.24 & \\
Average days stay men & 7.71 & \\
PCI men & 4.136 & \\
PCI women & 1.191 & \\
Thrombolysis men & 2.563 & \\
Thrombolysis women & 784 & \\
Temporary pacing & 386 & \\
Heart massage & 569 & \\
Mechanical support (IABP or other) & 426 & \\
Intubation & 674 & \\
Defibrillation & 708 & \\
Patients treated on ICU & 9.569 & \\
Average days on ICU & 2.11 &
\end{tabular}

63.20 years, and in females $71.36 \pm 12.32$ years; median 73.66 years; $p<0.001)$. The age distribution is illustrated in Fig. 2.

The most frequent risk factors were age (older than 65 years; 52.7\%), dyslipidemia (50.1\%), hypertension $(49.4 \%)$, weight (BMI $\left.>25 \mathrm{~kg} / \mathrm{m}^{2} ; 47 \%\right)$, current or former smoking (39.7\% respectively $21.4 \%$ ) and a medical history of cardiac events $(27.4 \%)$.

Of these patients, 8.490 were in Killip class I (73\%), 2.045 were coded for Killip class II while the rest of the population had been in class III $(n=550)$ and IV $(=336)$. The Killip classification is a score to risk stratify individuals with an acute myocardial infarction. Killip class I includes individuals with no clinical signs of heart failure; Killip class II includes individuals with rales in the lungs, an S 3 gallop, and elevated jugular venous pressure; Killip class III describes individuals with frank pulmonary edema; Killip class IV describes individuals in cardiogenic shock [17].

In-hospital procedures and events

In hospital procedures and outcomes are displayed in Table 4. PCI was performed in $5.327(45.83 \%)$ cases while 3.347 patients $(28.80 \%)$ received thrombolysis. Nine thousand five hundred sixty nine patients $(82.33 \%)$ were treated in an intensive care unit. There were 1.024 cases of in hospital deaths $(8.81 \%)$, whereas 10.597 (91.19\%) were successfully treated.

Three thousand four hundred forty seven patients (29.6\%) had complications during the hospital stay. Of these patients, $10.2 \%(n=1.185)$ went into a cardiogenic shock, $14.1 \%(n=$ 1.640) had recurrent ischemic episodes. $0.7 \%(n=87)$ were admitted for unstable angina but had an acute infarction, $3.2 \%(n=376)$ suffered from a re-infarction and 3.3\% $(n=$ 386) sustained a cerebrovascular event. In our study $3.3 \%$ $(n=386)$ of the patients required temporary pacing, $4.9 \%$ $(n=569)$ needed heart massage and 3.7\% $(n=426)$ were under mechanical circulatory support. Invasive mechanical ventilation was performed in $5.8 \%(n=674)$ of the study population and $6.1 \%(n=708)$ of the patients were defibrillated. The average length of stay in the ICU was 2.11 days (range 0-48 days, standard deviation (SD): 1.947; 95\% confidence interval [CI] between 2.07 to 2.14 ).

Outcomes and predictors of costs

The hospital length of stay varied from zero to 129 days with a mean of 9.48 days (median 8.0 days). Women had a mean stay of 11.24 days (median 10 days, SD 8.61) while men spent an average period of 8.87 days (median 8.0 days, SD 7.71) in the hospital $(p<0.0001)$.

Based on this length of stay the hospital costs (board and lodging) accounted for a mean of 6.906 Euro (median 5.713 Euro) with a range from zero to 105.281 Euro (SD: 6.632 Euro). The percentiles calculated are as follows: 25th percentile: 1.632 Euro, 50th percentile: 5.713 Euro, 75th percentile: 9.794 Euro. In 9.569 patient cases the additional costs for ICU have been added. This expense component amounted to a mean of 4.150 Euro and a median of 2.435 Euro. The standard deviation was 4.717 Euro while the range varied from zero to 116.903 Euro. Expenses for PCI and thrombolysis were calculated to be 1.548 Euro and 1.161 Euro.

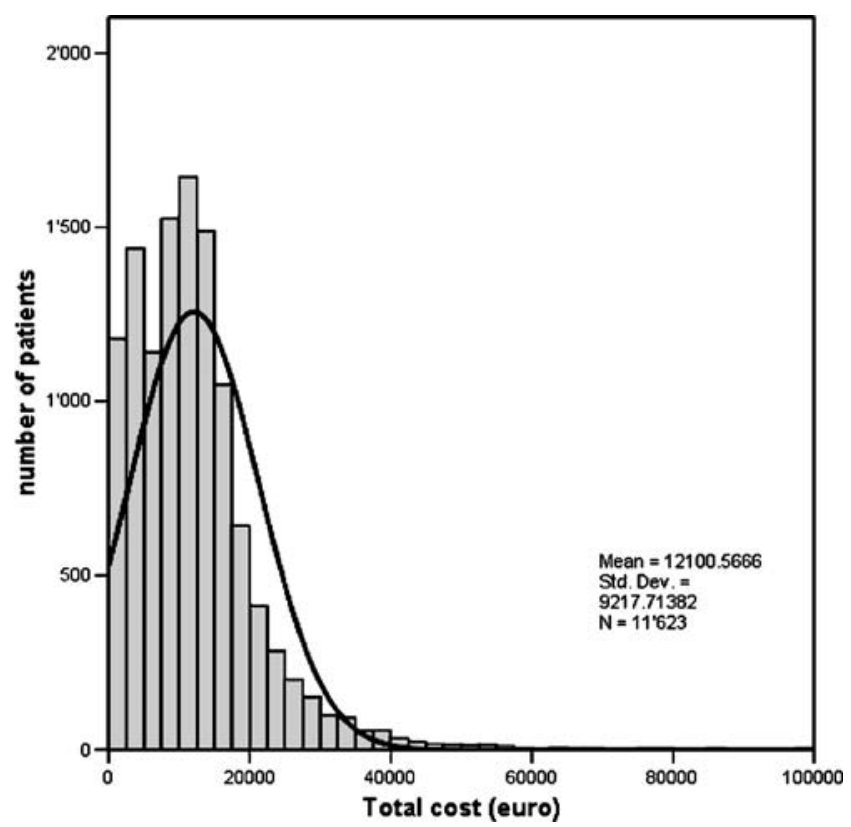

Fig. 1 Distribution of costs per treated ACS patient 
The mean cost per patient for each resource category is reported in Table 2 .

Based on calculations using data from official Swiss national statistics (Table 1) the total expenditures per patient varied between 0 Euro and 169.052 Euro with a mean of 12.101 Euro, a median of 10.929 Euro and a SD of 9.217 Euro. The 25th percentile was 5.960 Euro, the 50th was 10.929 Euro and the 75th was 15.494 Euro. The distribution of costs is depicted in Fig. 1.

The outcomes of co-morbidities and costs can be seen in the univariate analysis in Table 5.

Multivariate linear regression adjusting for the classification of high cost patients was performed afterwards and is displayed in Table 6.

Of all the variables included in the model, the strongest predictors of high-cost patient care was gender $(p=0.005)$, age $(p=0.017)$, cerebrovascular disease $(p=0.001)$ and diabetes $(p<0.0001)$.

More than $60 \%$ of hospital costs are associated with ward costs. A mean length of stay ( 9 days) on a normal ward costs
7.344 Euro. Diabetes and cerebrovascular disease increase the costs about $20-40 \%$.

Female patients have higher treatment costs than males however they had a higher mean age confound to be a risk factor.

\section{Discussion}

Hospital costing methods that adjust for differences in length of stay require a significant large sample to attain statistical power [18]. Our analysis is based on the data of more than 10.000 patients. By including statistics from the majority of hospitals in Switzerland, the AMIS registry reflects a realistic pattern of the present cost calculation in the management of ACS in the country. Findings about reperfusion therapy of myocardial infarction and the association of dyslipidemia and concomitant risk factors with in hospital mortality in ACS have been derived from data on this registry $[12,19]$. This ongoing multicenter project, which offers a data input and analysis over the internet, is a

Table 5 Univariate analysis of the effect of co-morbidities on costs

\begin{tabular}{|c|c|c|c|c|c|}
\hline Factor & & Cost (median), Euros & $\Delta$ cost & Interquartile ranges & $p$ values \\
\hline \multirow[t]{2}{*}{ Sex } & Women & 11.426 & 842 & 11.745 & $<0.0001$ \\
\hline & Men & 10.584 & & 9.048 & \\
\hline \multirow[t]{2}{*}{ Age } & $<65$ & 10.500 & 900 & 8.136 & $<0.0001$ \\
\hline & $\geq 65$ & 11.400 & & 9.436 & \\
\hline \multirow[t]{2}{*}{ BMI } & $<25$ & 10.513 & 97 & 8.483 & 0.929 \\
\hline & $\geq 25$ & 10.610 & & 8.148 & \\
\hline \multirow[t]{2}{*}{ Insurance } & Basic & 9.226 & 13 & 8.161 & 0.197 \\
\hline & Private & 9.213 & & 7.591 & \\
\hline \multirow[t]{2}{*}{ Smoking } & Yes & 10.583 & 746 & 7.373 & 0.001 \\
\hline & No & 11.329 & & 9.429 & \\
\hline \multirow{2}{*}{ ST-elevation } & Yes & 10.929 & 319 & 8.148 & 0.835 \\
\hline & No & 10.610 & & 10.160 & \\
\hline \multirow{2}{*}{ Heart rhythm } & Sinus rhythm & 9.697 & 1.632 & 8.148 & 0.001 \\
\hline & Atrial fibrillation & 11.329 & & 8.929 & \\
\hline \multirow[t]{2}{*}{ Prior myocardial infarction } & Yes & 10.500 & 0 & 9.944 & 0.23 \\
\hline & No & 10.500 & & 8.136 & \\
\hline \multirow[t]{2}{*}{ Co-morbidities } & Yes & 9.755 & 542 & 10.168 & 0.001 \\
\hline & No & 9.213 & & 7.332 & \\
\hline \multirow[t]{2}{*}{ Chronic heart failure } & None, NYHA I + II & 9.697 & 1.115 & 8.148 & 0.808 \\
\hline & NYHA III + IV & 8.977 & & 13.265 & \\
\hline \multirow[t]{2}{*}{ Peripheral vascular disease } & Yes & 10.555 & 871 & 12.255 & 0.037 \\
\hline & No & 9.684 & & 8.148 & \\
\hline \multirow[t]{2}{*}{ Cerebrovascular disease } & Yes & 12.132 & 2.822 & 10.500 & $<0.0001$ \\
\hline & No & 9.310 & & 8.148 & \\
\hline \multirow[t]{2}{*}{ Diabetes } & Yes & 11.316 & 2.103 & 10.051 & $<0.0001$ \\
\hline & No & 9.213 & & 8.136 & \\
\hline \multirow[t]{2}{*}{ Renal disease } & Yes & 9.761 & 77 & 13.225 & 0.299 \\
\hline & No & 9.684 & & 8.148 & \\
\hline \multirow[t]{2}{*}{ Hypertension } & Yes & 11.303 & 445 & 8.952 & 0.064 \\
\hline & No & 10.858 & & 7.677 & \\
\hline \multirow[t]{2}{*}{ Dyslipidemia } & Yes & 10.858 & 471 & 7.816 & 0.87 \\
\hline & No & 11.329 & & 8.965 & \\
\hline
\end{tabular}


Table 6 Multivariate linear regression for classification of high costs

\begin{tabular}{|c|c|c|c|c|c|}
\hline & \multirow{2}{*}{$\begin{array}{l}\text { Standardized coefficients } \\
\text { Beta }\end{array}$} & \multirow[t]{2}{*}{$t$} & \multirow[t]{2}{*}{ Sig. } & \multicolumn{2}{|c|}{$95 \%$ Confidence interval for B } \\
\hline & & & & Lower bound & Upper bound \\
\hline (Constant) & & 6.255 & 0.000 & 6.088 .496 & 11.648 .250 \\
\hline Sex & -0.045 & -2.802 & 0.005 & -1.615 .652 & -285.340 \\
\hline Age & 0.045 & 2.382 & 0.017 & 5.478 & 56.431 \\
\hline BMI & -0.012 & -0.732 & 0.464 & -791.254 & 360.957 \\
\hline Insurance & 0.013 & 0.860 & 0.390 & -444.277 & 1.138 .364 \\
\hline Smoking & 0.026 & 1.495 & 0.135 & -83.280 & 618.511 \\
\hline Prior myocardial infarction & -0.012 & -0.729 & 0.466 & -868.767 & 397.949 \\
\hline Co-morbidities & -0.014 & -0.697 & 0.486 & -979.094 & 465.300 \\
\hline Chronic heart failure (NYHA III + IV) & 0.023 & 1.411 & 0.158 & -436.858 & 2.678 .008 \\
\hline Peripheral vascular disease & 0.011 & 0.659 & 0.510 & -966.456 & 1.945 .655 \\
\hline Cerebrovascular disease & 0.056 & 3.472 & 0.001 & 1.013 .451 & 3.642 .843 \\
\hline Diabetes & 0.069 & 3.839 & 0.000 & 861.116 & 2.659 .007 \\
\hline Renal disease & 0.030 & 1.845 & 0.065 & -77.520 & 2.553 .083 \\
\hline Hypertension & -0.010 & -0.578 & 0.564 & -751.155 & 409.276 \\
\hline Dyslipidemia & 0.030 & 1.912 & 0.056 & -14.066 & 1.116 .772 \\
\hline
\end{tabular}

$F(14,4139)=6.15 ; p>; F=0.0001 ; R^{2}=0.143 ;$ adjusted

$R^{2}=0.017$

useful tool to examine actual trends in cardiology and asses their impact on costs.

Our analysis is the first to focus on current costs in treating ACS in face of the upcoming DRG implementation in Switzerland and helps to predict high cost individuals.

Several crucial findings have emerged from this analysis. First, we estimate the average cost of hospital treatment for ACS to be about 12.101 Euro. These results appear to be in line with the findings of other investigations $[6,7,20,21]$. Levy et al. described an amount of 12.393 Euro for the cost of treating a myocardial infarction in the Swiss population. Their estimation, however, was based on a smaller sample size [7]. Matsui and colleagues found the same duration of stay in the intensive care unit (two days) in the late nineties, but a longer hospitalization on the general ward in Switzerland (12 days). This reflects the trend towards shorter residence periods on the general ward over the last years $[6,22]$. In addition Gandjour et al. [21] calculated the personal costs on the critical care unit (physician hour 34.91 Euro; nursing hour 28.90 Euro) and general medicine ward (physician hour 34.91 Euro; nursing hour 24.07 Euro). This model could act as a valuable tool for further detailed investigations of personnel expenditures.

Several important hospital resource benchmarks for a DRG implementation can be derived from our findings. This study found that the average cost of co-morbidities like diabetes and cerebrovascular disease are higher than for other secondary disorders.

The coding of both accompanying diseases should allow for a higher reimbursement rate as they require a longer and more expensive stay.
Females have a higher cost of treatment than males, but represent an older set in our analyzed population. Age per se was an indicator for higher charges and presupposes adjusted DRG codes (Fig. 2). Besides the identified comorbidities, gender and age, the length of stay, obviously influences the total expenses. There are opportunities to improve the efficiency in the treatment of ACS. International studies recorded in European countries indicate longer hospital stays and the more conservative use of early discharge [23]. There is potential economic benefit of an earlier discharge for low-risk patients, but they must be balanced against a medical risk and a cost shift to the outpatient area. Integration between inpatient and outpatient care could result in a better outcome of post myocardial infarction management and should be improved before entering the DRG system. Since the release of the ACC/AHA Guideline recommendations for treatment of NON STEMI ACS, hospital prescription of clopidogrel in patients with NON STEMI ACS who are treated with medical therapy alone and those who undergo cardiac artery bypass graft surgery (CABG) have increased. Most of these patients still do not receive clopidogrel at discharge even though it is investigated to be cost-effective [24, 25]. A time based risk management for post myocardial infraction guides decision-making and supports a discharge of four days after uncomplicated myocardial infarction. Hospitalization of patients beyond three days is uneconomical by conventional standards [26, 27]. Appropriate procedures and quick execution during the first hospital stay would lead to global economic savings for the public health system and could be clinically advantageous for the patient. 


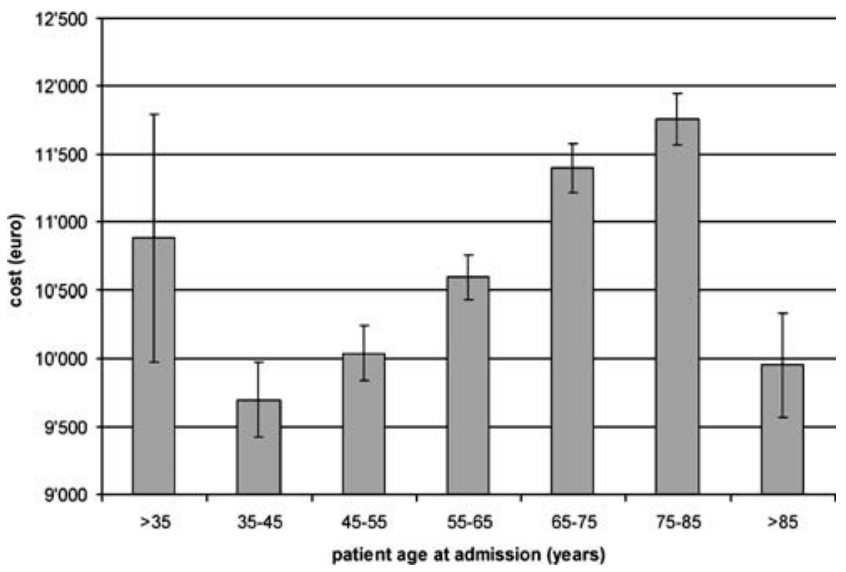

Fig. 2 Median costs per treated ACS patient by age group

Hospitalization is the focal point in the DRG system and hence the value is basically independent of the hospital. One critical point when using the DRG system is how to correctly detect the classification of the patient during the entire hospital stay (Table 7). Depending on the institution and the first coding, a diagnosis might be a primary or a secondary one. The diagnosis may also vary depending on the type of department seeing the patient first. Therefore a bias in the patient DRG can occur. In the preparing for the DRG system the clinician has to cope with a lot of new tasks. On the one hand all clinical findings have to be coded and documented accurately. Knowledge about the economic significance of the coding for the hospital and the health care system is of particular importance. An important consideration is the improvement of clinical procedures and their time flow. Only hospitals that can work efficiently before the expiration of the given DRG term will be able to survive the severe competition. Based on experience in this new field, many direct measures to optimising efficiency can be taken. Labour efficiency and the use of standardized operational sequences could provide economic gain without a loss in health care quality. The coding of secondary diagnosis is also crucial if reimbursements have to cover real costs.

\section{Limitations}

At the time of this study, 65 of 106 hospitals treating ACS in Switzerland took part in the AMIS registry. This number varied during the survey and may therefore not be entirely representative for all hospitals in the country. Accordingly, the absolute number of patients in this analysis may not correspond to the national incidence of ACS leading to hospitalization. Costly technology improvements and other procedures (e.g. new costly drug eluting stents and cardiac artery bypass graft surgery) have not been accounted for in this survey. Only direct hospital costs have been analyzed and estimated from billed charges. It is unlikely that our approaches would consistently over- or underestimate the cost of treating patients. Our method of assigning DRGs may not capture all cost-relevant aspects. Our perspective prevents any conclusion regarding the total health care or social costs for these patients. The German (G)-DRG

Table 7 Comparison of present costs and potential DRG reimbursement categories (adapted from the German [G]-DRG system) [28]

\begin{tabular}{|c|c|c|c|c|}
\hline G-DRG & Description & $\begin{array}{l}\text { Relation and } \\
\text { valuation factor }\end{array}$ & $\begin{array}{l}\text { Reference value } \\
\text { in Euro (2007) }\end{array}$ & $\begin{array}{l}\text { Average amount } \\
\text { in Euro }\end{array}$ \\
\hline F 52 B & $\begin{array}{l}\text { Invasive diagnostic in acute myocardial infarction } \\
\text { with complex PCI + Stent intervention, five days } \\
\text { hospital stay, thereof one day } \mathrm{ICU}^{\mathrm{b}}\end{array}$ & 1.490 & $2.735,50$ & $4.075,90$ \\
\hline $\begin{array}{l}\text { Current Swiss accounting } \\
\text { system }\end{array}$ & $\begin{array}{l}\text { Invasive diagnostic in acute myocardial infarction } \\
\text { with complex PCI + Stent intervention, five days } \\
\text { hospital stay, thereof one day } \mathrm{ICU}^{\mathrm{c}}\end{array}$ & & & $\begin{array}{l}\text { Average amount } \\
\text { in Euro } \\
12.101^{\mathrm{d}}\end{array}$ \\
\hline \multicolumn{5}{|l|}{$\begin{array}{l}\text { Other possible G-DRG } \\
\text { codings in ACS patients } \\
\text { receiving angiography }\end{array}$} \\
\hline F 52 A & Like F 52 B plus three severe co-morbidities & 2.257 & $2.735,50$ & $6.174,02$ \\
\hline F 24 A & Very complex PCI plus three severe co-morbidities & 2.784 & $2.735,50$ & $7.615,63$ \\
\hline F $24 \mathrm{C}$ & Like F 24 A without severe co-morbidities & 1.910 & $2.735,50$ & $5.224,81$ \\
\hline F $41 \mathrm{~A}$ & Invasive diagnostic in ACS with severe co-morbidities & 2.120 & $2.735,50$ & $5.799,26$ \\
\hline F $41 \mathrm{~B}$ & Like F 41 A without severe co-morbidities & 1.257 & $2.735,50$ & $3.438,52$ \\
\hline
\end{tabular}

\footnotetext{
${ }^{\text {a }}$ Depending on hospital size and department

${ }^{\mathrm{b}}$ Except separate ICU charge (only charged after 7 days)

${ }^{c} 1$ day ICU included (2.435 Euro)

${ }^{\mathrm{d}}$ Nationwide average for Switzerland
} 
system, which has been bought by Swiss DRG and adapted for Switzerland, is based on a dual financing. Investments e.g. buildings or equipment is funded by the federal government and not included in the G-DRGs. Follow-up was not available in this project, however a long term followup questionnaire is being prepared and the outcomes will soon be reported. Because of rapid evolutions of medical technology and the accelerated progress in medical knowledge, cost determination analyses have limited half-lives and have to be updated continuously.

Public health policy is in great need of large high quality national databases. Cost information in these models can serve to focus attention on the assumptions underlying clinical practice patterns and can help to identify areas in which there is substantial disagreement about appropriate evaluation and treatment strategies. The findings of analytic models should be integrated into medical practice. They can be used practically for physicians treating patients and developing guidelines. They can also be used conceptually for public health authorities to guide decision making in healthcare systems.

To the best of our knowledge this analysis represents the first effort to quantify the cost of hospitalization relating comorbidities, duration of stay and procedures for ACS in a nationwide Swiss survey for an adapted G-DRG implementation. This country- specific cost model has relevance for budgetary and planning purposes. The data can be used by decision makers to asses the value and costs of therapies and the impact of policy changes on patients with ACS. Some of the determined predictors of high costs are preventable co-morbidities and identify the importance of prevention campaigns addressing the cardiometabolic risk factors.

Additional efforts investigating long term outcomes and the burden for ambulatory treatment are needed to determine a more exact cost-structure for a DRG implementation. Setting up and testing outpatient systems for adequate treatment as well as cost calculations are a prerequisite before the introduction of DRGs.

Acknowledgements We like to thank Dipl. oec. Mathias Larbig for G-DRG advice, Dr. Konstantin J. Dedes for statistical support and Kenneth W. Schneider MS for proofreading the manuscript.

Conflict of interest None declared.

\section{References}

1. Leal J, Luengo-Fernandez R, Gray A, Petersen S, Rayner M. Economic burden of cardiovascular diseases in the enlarged European Union. Eur Heart J 2006;27:1610-9, Jul.
2. Schweizerische Eidgenossenschaft, Bundesamt für Statistik, Junker C. Todesursachenstatistik, Ursachen der Sterblichkeit 2001 und 2002. http://www.bfs.admin.ch/bfs/portal/de/index.html (June 2006).

3. Schweizerische Eidgenossenschaft, Bundesamt für Statistik, Perret A. Tabellen der Gesundheitsstatistik Medizinische Statistik 2004 Resultate (Standardtabellen) Neuchâtel 2006, http://www.bfs. admin.ch/bfs/portal/de/index.html (June 2006).

4. Schweizerische Eidgenossenschaft, Bundesamt für Statistik, Gerber Y-A. Kosten und Finanzierung des Gesundheitswesens 2003 BFS Statistik der Schweiz Neuchâtel 2006. http://www.bfs. admin.ch/bfs/portal/de/index.html (June 2006).

5. Grech $\mathrm{ED}$. ABC of interventional cardiology: percutaneous coronary intervention. II: the procedure. BMJ 2003;326:1137-40.

6. Matsui K, Polanczyk CA, Gaspoz JM, Theres H, Kleber FX, Sobashima A, et al. Management of patients with acute myocardial infarction at five academic medical centers: clinical characteristics, resource utilization, and outcome. J Investig Med 1999;47:134-40.

7. Levy E, Gabriel S, Dinet J. The comparative medical costs of atherothrombotic disease in European countries. Pharmacoeconomics 2003;21:651-9.

8. Schweizerische Eidgenossenschaft, Bundesamt für Statistik, Durchschnittlich angepasste Kosten pro Pflegetag im Akutbereich 1999-2003 gewichtet durch den Case Mix 2003 http://www.bfs. admin.ch/bfs/portal/de/index.html (June 2006).

9. UBS Quotes; http://wb1.ubs.com/cache/fin/pub/gvu/quotes/ markets_instruments/?locale=en_US (May 2006).

10. Patel MR, Chen AY, Peterson ED, Newby LK, Pollack CV, Jr, Brindis RG, et al. Prevalence, predictors, and outcomes of patients with non-ST-segment elevation myocardial infarction and insignificant coronary artery disease: results from the Can Rapid risk stratification of Unstable angina patients Suppress ADverse outcomes with Early implementation of the ACC/AHA Guidelines (CRUSADE) initiative. Am Heart J 2006;152:641-7.

11. Assmann G, Cullen P, Schulte H. Simple scoring scheme for calculating the risk of acute coronary events based on the 10-year follow-up of the prospective cardiovascular Munster (PROCAM) study. Circulation 2002;105:310-5.

12. Radovanovic D, Erne P, Schilling J, Noseda G, Gutzwiller F. Association of dyslipidemia and concomitant risk factors with inhospital mortality in acute coronary syndrome in Switzerland. HeartDrug 2005;5:131-139.

13. Erhardt L, Herlitz J, Bossaert L, Halinen M, Keltai M, Koster R, et al. Task force on the management of chest pain. Eur Heart $J$ 2002;23:1153-76.

14. Bertrand ME, Simoons ML, Fox KA, Wallentin LC, Hamm CW, McFadden E, et al. Management of acute coronary syndromes in patients presenting without persistent ST-segment elevation. Eur Heart J 2002;23:1809-40.

15. Van de Werf F, Ardissino D, Betriu A, Cokkinos DV, Falk E, Fox KA, et al. Management of acute myocardial infarction in patients presenting with ST-segment elevation. The Task Force on the Management of Acute Myocardial Infarction of the European Society of Cardiology. Eur Heart J 2003;24:28-66.

16. Silber S, Albertsson P, Aviles FF, Camici PG, Colombo A, Hamm C, et al. Guidelines for percutaneous coronary interventions. The task force for percutaneous coronary interventions of the european society of cardiology. Eur Heart J 2005;26:804-47.

17. Killip T, Kimball JT. Treatment of myocardial infarction in a coronary care unit: a two year experience of 250 patients. Am J Cardiol 1967;20:457-64.

18. Reed SD, Friedman JY, Gnanasakthy A, Schulman KA. Comparison of hospital costing methods in an economic evaluation of a multinational clinical trial. Int J Technol Assess Health Care 2003; 19:396-406.

19. Fassa AA, Urban P, Radovanovic D, Duvoisin N, Gaspoz JM, Stauffer JC, et al. Trends in reperfusion therapy of ST segment 
elevation myocardial infarction in Switzerland: six year results from a nationwide registry. Heart 2005;91:882-8.

20. Kauf TL, Velazquez EJ, Crosslin DR, Weaver WD, Diaz R, Granger $\mathrm{CB}$, et al. The cost of acute myocardial infarction in the new millennium: evidence from a multinational registry. Am Heart J 2006;151:206-12.

21. Gandjour A, Kleinschmit F, Lauterbach KW. European comparison of costs and quality in the treatment of acute myocardial infarction (2000-2001). Eur Heart J 2002;23:858-68.

22. Mark DB, Newby LK. Early hospital discharge after uncomplicated myocardial infarction: are further improvements possible? Eur Heart J 2003;24:1613-5.

23. Kaul P, Newby LK, Fu Y, Mark DB, Califf RM, Topol EJ, et al. International differences in evolution of early discharge after acute myocardial infarction. Lancet 2004;363:511-7.

24. Tricoci P, Roe MT, Mulgund J, Newby LK, Smith SC, Jr, Pollack $\mathrm{CV}$, Jr, et al. Clopidogrel to treat patients with non-ST-segment elevation acute coronary syndromes after hospital discharge. Arch Intern Med 2006;166:806-11.

25. Bramkamp M, Dedes KJ, Szucs TD. Pharmacotherapy of acute coronary syndromes: medical economics with an emphasis on clopidogrel. Cardiovasc Drugs Ther 2005;19:291-9.

26. Newby LK, Hasselblad V, Armstrong PW, Van de Werf F, Mark DB, White HD, et al. Time-based risk assessment after myocardial infarction. Implications for timing of discharge and applications to medical decision-making. Eur Heart J 2003;24: 182-9.

27. Newby LK, Eisenstein EL, Califf RM, Thompson TD, Nelson CL, Peterson ED, et al. Cost effectiveness of early discharge after uncomplicated acute myocardial infarction. N Engl J Med 2000; 342:749-55.

28. InEK gGmbH, German Refined-Diagnosis Related Groups, Definitionshandbuch G-DRG-Version 2007-Fassung vom 06.12.2006, http://www.g-drg.de/ (January 2007). 